University of Nebraska - Lincoln

DigitalCommons@University of Nebraska - Lincoln

Faculty Publications from Nebraska Center for

Materials and Nanoscience, Nebraska Center Materials and Nanoscience

for (NCMN)

2009

\title{
Rapidly Solidified Sm-Co-V Nanocomposite Permanent Magnets
}

R. S. K. Valiveti

University of Nebraska - Lincoln

A. Ingmire

University of Nebraska - Lincoln

Jeffrey E. Shield

University of Nebraska - Lincoln, jshield@unl.edu

Follow this and additional works at: https://digitalcommons.unl.edu/cmrafacpub

Part of the Nanoscience and Nanotechnology Commons

Valiveti, R. S. K.; Ingmire, A.; and Shield, Jeffrey E., "Rapidly Solidified Sm-Co-V Nanocomposite Permanent Magnets" (2009). Faculty Publications from Nebraska Center for Materials and Nanoscience. 92.

https://digitalcommons.unl.edu/cmrafacpub/92

This Article is brought to you for free and open access by the Materials and Nanoscience, Nebraska Center for (NCMN) at DigitalCommons@University of Nebraska - Lincoln. It has been accepted for inclusion in Faculty Publications from Nebraska Center for Materials and Nanoscience by an authorized administrator of DigitalCommons@University of Nebraska - Lincoln. 


\title{
Rapidly solidified Sm-Co-V nanocomposite permanent magnets
}

\author{
R. S. K. Valiveti, A. Ingmire, and J. E. Shield ${ }^{\text {a) }}$ \\ Department of Mechanical Engineering, Nebraska Center for Materials and Nanoscience, \\ University of Nebraska-Lincoln, Nebraska 68588, USA
}

(Presented 14 November 2008; received 17 September 2008; accepted 2 December 2008; published online 11 March 2009)

\begin{abstract}
Alloys around the Sm-Co eutectic composition provide an opportunity to form two-phase nanocomposite permanent magnets consisting of nanoscale Co fibers embedded in $\mathrm{Sm}_{2} \mathrm{Co}_{17}$. While ternary alloying elements may refine the scale of the structure, they may also disrupt the eutectic growth and lead to the formation of primary Co. Thus, microstructural selection maps were constructed for conventionally solidified $\mathrm{Sm}-\mathrm{Co}-\mathrm{V}$ alloys. It was found that $\mathrm{V}$ additions enlarged the primary $\mathrm{Sm}_{2} \mathrm{Co}_{17}$-forming region and, at $\left(\mathrm{Sm}_{0.09} \mathrm{Co}_{0.91}\right)_{97} \mathrm{~V}_{3}$, resulted in a eutectic structure. Upon rapid solidification, this alloy was determined to have a coercivity of $5 \mathrm{kOe}$ with a high remanent ratio. However, the $\mathrm{V}$ addition reduced the magnetization, which limited the energy product to 4.3 MG Oe. The rapidly solidified structure consisted of primary $\mathrm{SmCo}_{7} \mathrm{dendrites} \mathrm{along}$ with an intergranular Co region, suggesting that eutectic structure formation is skewed by underlying metastable phase relationships. (C) 2009 American Institute of Physics.
\end{abstract}

[DOI: 10.1063/1.3073847]

\section{INTRODUCTION}

Nanocomposite permanent magnets continue to attract interest because of the need for stronger permanent magnets, and exchange-spring permanent magnets offer the best opportunity to increase energy products. ${ }^{1}$ Of the rare earth permanent magnets, $\mathrm{Nd} / \mathrm{Pr}-\mathrm{Fe}-\mathrm{B}$ nanocomposite permanent magnets have received the most attention, primarily because of favorable phase relationships between soft and hard magnetic phases and the relative ease in producing nanoscale structures. Sm-Co-based alloys, however, are attractive for elevated temperature applications due to the high Curie temperatures of the relevant compounds. While mechanical milling has effectively produced $\mathrm{Sm}-\mathrm{Co}$-based nanocomposite permanent magnets, ${ }^{2}$ melt processing has proved more challenging. Rapid solidification of binary Sm-Co alloys results in relatively coarse grain structures, ${ }^{3-5}$ although heavily alloyed materials have produced the desired nanoscale twophase structure. ${ }^{6-9}$ These latter materials form a granular composite, with individual grains of the soft and hard magnetic phases. More recently, it was proposed ${ }^{10}$ and shown ${ }^{11}$ that it is only necessary for the soft magnetic phase to be at the nanoscale for effective exchange-coupled permanent magnets. Phase relationships in the Sm-Co system offer an opportunity to construct two-phase structures with the soft magnetic phase embedded in the hard magnetic phase through the fibrous eutectic phase transformation at approximately 8 at. $\%$ Sm. ${ }^{12}$ Co fibers with $\sim 25 \mathrm{~nm}$ diameter were observed in rapidly solidified Sm-Co. However, insufficient hardening resulted in low coercivity. ${ }^{13}$ The lack of hardening could be related to the coarse size of the hard magnetic phase, which allowed reversal via domain wall processes.

In this paper, microstructural selection maps for $\mathrm{Sm}-$

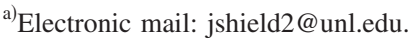

$\mathrm{Co}-\mathrm{V}$ alloys in the vicinity of the eutectic point were determined, along with the magnetic properties of the rapidly solidified alloys.

\section{EXPERIMENTAL PROCEDURES}

Alloy ingots with nominal compositions of $\left(\mathrm{Sm}_{x} \mathrm{Co}_{1-x}\right)_{100-y} \mathrm{~V}_{y}$ with $x=0.06-0.12$ and $y=0-3$ were arcmelted from high-purity elemental constituents. An extra 5\% Sm was added to account for vaporization losses during melting. Note that the binary eutectic between Co and $\mathrm{Sm}_{2} \mathrm{Co}_{17}$ occurs at approximately 8 at. $\% \mathrm{Sm}(x=0.08$ and $y=0$ in the above equation). ${ }^{12}$ Samples were remelted to ensure homogeneity. The arc-melted ingots were then sectioned for microscopy analysis by standard metallurgical polishing procedures and examined by optical and scanning electron microscopies, the latter using a Hitachi 4500 FESEM. Selected alloy compositions were also rapidly solidified by melt spinning in an $\mathrm{Ar}$ atmosphere at a tangential wheel speed of $30 \mathrm{~m} / \mathrm{s}$. The ribbons produced by melt spinning were ground for x-ray diffraction analysis and analyzed using a Rigaku Multiflex x-ray diffractometer with a $\mathrm{Cu}$ x-ray source. Transmission electron microscopy was performed using a JEOL 2010 operating at $200 \mathrm{kV}$ on ribbons thinned by ion milling with a precision ion polishing ystem at $4.5 \mathrm{kV}$.

\section{RESULTS AND DISCUSSION}

In the vicinity of a eutectic point, three basic assolidified microstructures are possible. Hypoeutectic compositions result in the formation of primary Co dendrites, eutectic compositions form eutectic microstructures, and hypereutectic compositions result in the formation of primary $\mathrm{Sm}_{2} \mathrm{Co}_{17}$ dendrites. Primary Co dendrites are easily distinguishable from primary $\mathrm{Sm}_{2} \mathrm{Co}_{17}$ dendrites using microscopy techniques, ${ }^{13}$ as they appear lighter and more cir- 


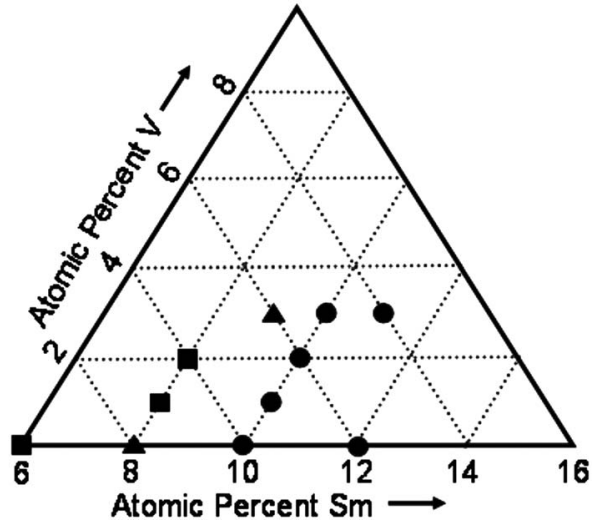

FIG. 1. Microstructural selection map for Sm-Co-V alloys. Squares indicate primary $\mathrm{Co}$, circles indicate primary $\mathrm{Sm}_{2} \mathrm{Co}_{17}$, and triangles indicate eutectic structures.

cular and have obvious side branches (i.e., the Co has less secondary arm thickening) under the optical microscope.

We determined the primary solidification product of each of the arc-melted alloys (Fig. 1). It is necessary to avoid primary Co dendrites, as their coarse structure deleteriously influences the magnetic properties. The principal finding here is that the addition of $\mathrm{V}$ maintained, and even broadened, the region of primary $\mathrm{Sm}_{2} \mathrm{Co}_{17}$ solidification. Second, a fibrous eutectic structure was observed at $\left(\mathrm{Sm}_{0.09} \mathrm{Co}_{0.91}\right)_{97} \mathrm{~V}_{3}$, with fiber diameters of approximately $500 \mathrm{~nm}$ (Fig. 2). The microstructures of surrounding compositions were also consistent with a eutectic point, evidenced by primary $\mathrm{Sm}_{2} \mathrm{Co}_{17}$ with an interdendritic eutectic structure. X-ray diffraction confirmed the presence of hcp Co and $\mathrm{Sm}_{2} \mathrm{Co}_{17}$ phases.

While the arc-melted ingots provided important information related to primary phase formation, the microstructural scale was too coarse for effective exchange coupling, which requires nanometer-scale grain sizes. Thus, the evaluation of arc-melted ingots provided guidance for selecting alloys for rapid solidification by melt spinning. First, the eutectic alloy $\left(\mathrm{Sm}_{0.09} \mathrm{Co}_{0.91}\right)_{97} \mathrm{~V}_{3}$ was melt spun at a tangential wheel speed of $30 \mathrm{~m} / \mathrm{s}$. X-ray diffraction revealed the presence of the $\mathrm{SmCo}_{7}$ structure; no reflections indicative of the ordered $\mathrm{Sm}_{2} \mathrm{Co}_{17}$ phase were observed. Also, no peaks corresponding to either fcc or hcp Co were observed. While the binary eutectic $\mathrm{Sm}_{8} \mathrm{Co}_{92}$ alloy displayed a coercivity of $800 \mathrm{Oe},{ }^{13}$

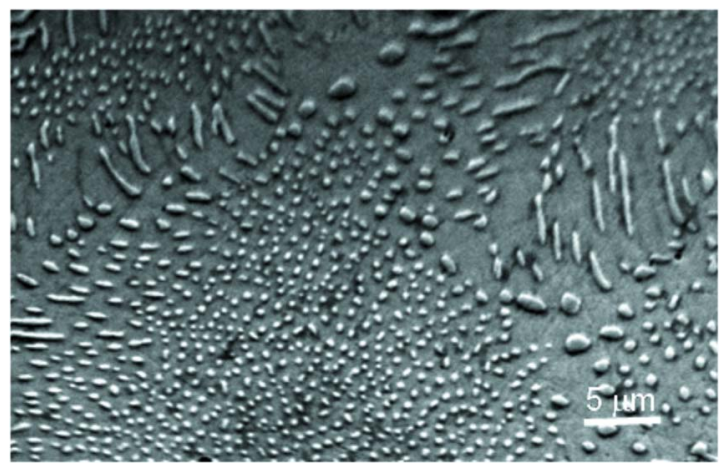

FIG. 2. (Color online) Scanning electron micrograph of $\left(\mathrm{Sm}_{0.09} \mathrm{Co}_{0.91}\right)_{97} \mathrm{~V}_{3}$ revealing a eutectic structure consisting of Co rods in a $\mathrm{Sm}_{2} \mathrm{Co}_{17}$ matrix.

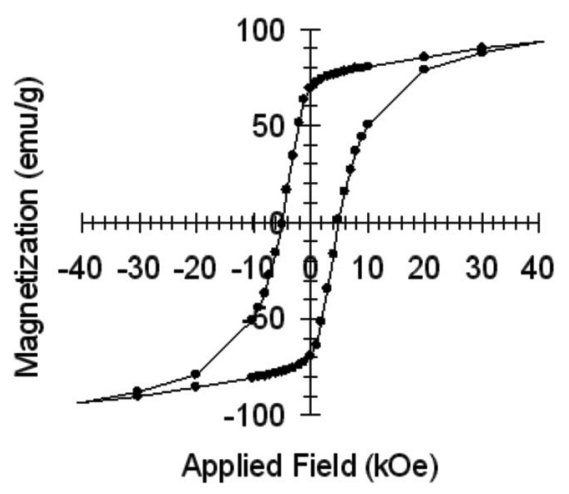

FIG. 3. Hysteresis loop for the rapidly solidified $\left(\mathrm{Sm}_{0.09} \mathrm{Co}_{0.91}\right)_{97} \mathrm{~V}_{3}$ alloy.

the coercivity of the $\left(\mathrm{Sm}_{0.09} \mathrm{Co}_{0.91}\right)_{97} \mathrm{~V}_{3}$ alloy was $5 \mathrm{kOe}$ and the remanent ratio was 0.7 (Fig. 3). However, the $\mathrm{V}$ addition reduced the magnetization, which limited the energy product to $4.3 \mathrm{MG}$ Oe.

Transmission electron microscopy revealed the formation of primary $\mathrm{SmCo}_{7}$ with a relatively coarse grain size of 400-500 nm and an interdendritic structure (Fig. 4). Selected area electron diffraction revealed that the interdendritic phase is hcp Co. Evidently, the volume fraction of hcp Co is too low in this alloy to be observed by x-ray diffraction. With the absence of an interdendritic eutectic structure, this microstructure is more consistent with a peritectic solidification path. The high coercivity may arise from the fact that the $\mathrm{SmCo}_{7}$ grains are below the single-domain limit, while the intergranular hcp Co provides remanence enhancement. Contrary to the arc-melted ingot, the eutectic structure is not the predominant microstructure. While the region of eutectic formation is expanded at high undercoolings, ${ }^{14,15}$ the underlying metastable phase relationships may result in the skewing of the eutectic-forming region and dendritic solidification at eutectic compositions. Apparently, that is the case here, and the composition $\left(\mathrm{Sm}_{0.09} \mathrm{Co}_{0.91}\right)_{97} \mathrm{~V}_{3}$ that produced a eutectic structure under conventional solidification results in primary $\mathrm{SmCo}_{7}$ formation at higher undercoolings. As a result, desirable phase formation, resulting in good hard magnetic properties, may occur at even more Co-rich compositions. Therefore, $\left(\mathrm{Sm}_{0.08} \mathrm{Co}_{0.92}\right)_{97} \mathrm{~V}_{3}$ and $\left(\mathrm{Sm}_{0.07} \mathrm{Co}_{0.93}\right)_{97} \mathrm{~V}_{3}$ alloys were melt spun at $30 \mathrm{~m} / \mathrm{s}$. X-ray diffraction analysis indicated an increasing amount of hcp Co along with $\mathrm{SmCo}_{7}$. The

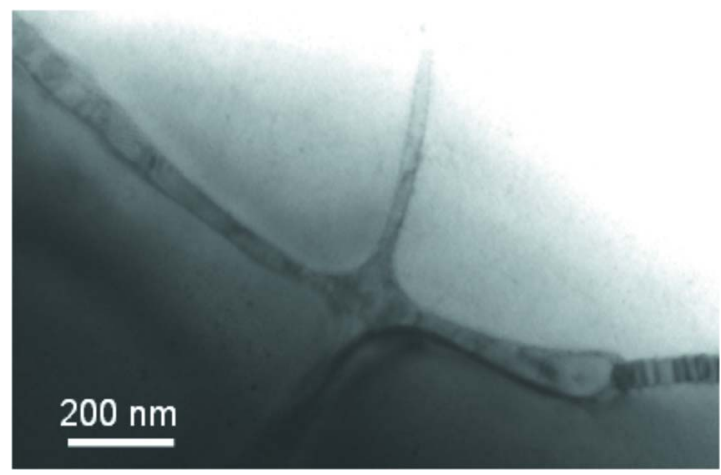

FIG. 4. (Color online) Transmission electron micrograph revealing primary formation of $\mathrm{SmCo}_{7}$ and an interdendritic structure. 
coercivity was observed to decrease with increasing Co content. The as-solidified coercivity of the $\left(\mathrm{Sm}_{0.08} \mathrm{Co}_{0.92}\right)_{97} \mathrm{~V}_{3}$ alloy was measured to be $2.9 \mathrm{kOe}$, while the as-solidified $\left(\mathrm{Sm}_{0.07} \mathrm{Co}_{0.93}\right)_{97} \mathrm{~V}_{3}$ had a coercivity of $1.43 \mathrm{kOe}$. Further work is necessary to understand the microstructural development in these materials.

\section{CONCLUSIONS}

The microstructural selection map in conventionally solidified $\mathrm{Sm}-\mathrm{Co}-\mathrm{V}$ alloys in the vicinity of the Sm-Co eutectic at 8 at. $\% \mathrm{Sm}$ was developed. The addition of $\mathrm{V}$ was found to enlarge the $\mathrm{Sm}_{2} \mathrm{Co}_{17}$-forming region, and a eutectic structure was observed at $\left(\mathrm{Sm}_{0.09} \mathrm{Co}_{0.91}\right)_{97} \mathrm{~V}_{3}$. Co-rich $\mathrm{Sm}-$ Co-based alloys were produced by rapid solidification with excellent hard magnetic properties. An alloy with a Co content of 89.3 at. \% and only 7.8 at. \% Sm was determined to have a coercivity of $2.9 \mathrm{kOe}$ after melt spinning, while an alloy containing 88.3 at. \% Co and 8.7 at. \% Sm had a coercivity of $5 \mathrm{kOe}$ in the as-solidified condition. In both cases, the primary phase formation during rapid solidification was the disordered $\mathrm{SmCo}_{7}$ structure. With the addition of $\mathrm{V}$, the formation of the hard magnetic phase is extended to lower Sm content.

\section{ACKNOWLEDGMENTS}

The authors gratefully acknowledge support for this work from the National Science Foundation under Grant Nos. DMR 0305354 and DMR 0804744.

${ }^{1}$ R. Skomski and J. M. D. Coey, Phys. Rev. B 48, 15812 (1993).

${ }^{2}$ P. A. I. Smith, J. Ding, P. G. McCormick, and R. Street, Scr. Mater. 34, 61 (1996).

${ }^{3}$ C. H. Chen, S. Kodat, M. H. Walmer, S. F. Cheng, M. A. Willard, and V. G. Harris, J. Appl. Phys. 93, 7966 (2003).

${ }^{4}$ S. K. Chen, M. S. Chu, and J. L. Tsai, IEEE Trans. Magn. 32, 4419 (1996).

${ }^{5} \mathrm{~V}$. K. Ravindran, "Phase selection and microstructure of rapidly solidified Sm-Co alloys," MS thesis, University of Nebraska, 2005.

${ }^{6}$ W. Manrakhan, L. Withanawasam, X. Meng-Burany, W. Gong, and G. C. Hadjipanayis, IEEE Trans. Magn. 33, 3898 (1997).

${ }^{7}$ S. S. Makridis, G. Litsardakis, I. Panagiotopoulos, D. Niarchos, Y. Zhang, and G. C. Hadjipanayis, IEEE Trans. Magn. 38, 2922 (2002).

${ }^{8}$ R. Gopalan, D. H. Ping, and K. Hono, J. Magn. Magn. Mater. 284, 321 (2004).

${ }^{9}$ S. S. Makridis, I. Panagiotopoulos, I. Tsiaoussis, N. Frangis, E. Pavlidou, K. Chrisafis, G. F. Papathanasiou, K. Efthimiadis, G. C. Hadjipanayis, and D. Niarchos, J. Magn. Magn. Mater. 320, 2322 (2008).

${ }^{10}$ J. E. Shield, J. Zhou, S. Aich, V. K. Ravindran, R. Skomski, and D. J. Sellmyer, J. Appl. Phys. 99, 08 B508 (2006).

${ }^{11}$ J. E. Shield, S. Aich, V. K. Ravindran, A. Hsaio, and L. H. Lewis, Scr. Mater. 52, 75 (2005).

${ }^{12}$ Alloy Phase Diagrams, edited by H. Baker (ASM International, Metals Park, OH, 1992).

${ }^{13}$ V. K. Ravindran and J. E. Shield, Metall. Trans. A 38A, 732 (2007).

${ }^{14}$ W. Kurz and R. Trivedi, Acta Metall. Mater. 38, 1 (1990).

${ }^{15}$ S. C. Gill, M. Zimmermann, and W. Kurz, Acta Metall. Mater. 40, 2895 (1992). 